
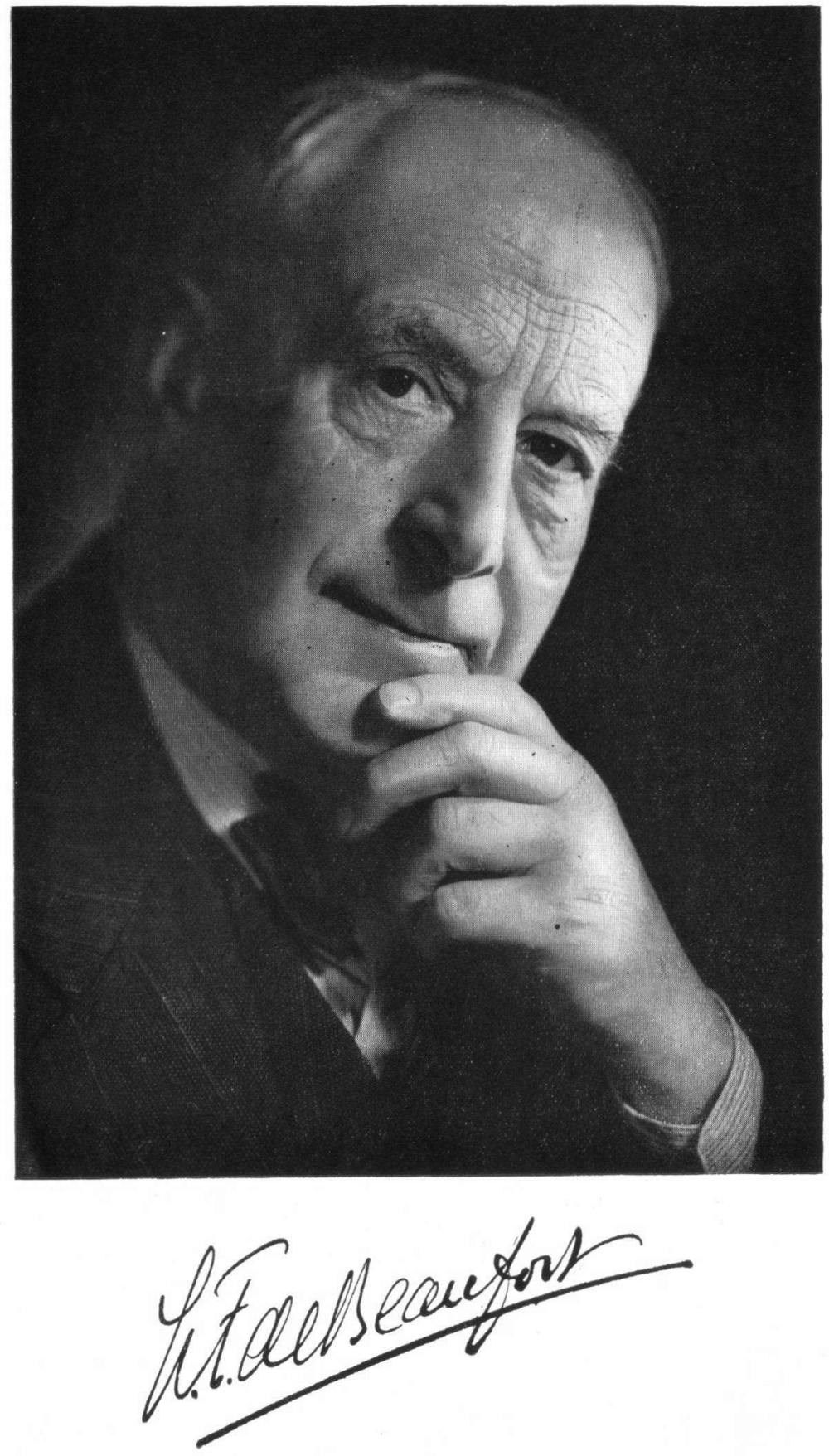

Downloaded from Brill.com๑4/26/2023 $02: 23: 33 \mathrm{PM}$

via free access 


\section{LIEVEN FERDINAND DE BEAUFORT}

Een feestnummer ter ere van het bereiken van de 70 -jarige leeftijd, een mijlpaal, en wel een zeer belangrijke mijlpaal in verband met het daaraan onafwendbaar verbondene emeritaat, verlangt een korte terugblik op alles wat tot nu toe bereikt werd, een verantwoording tevens van de aard dezer publicatie, die een hulde wil zijn van allen, die met de geleerde in aanraking kwamen, als collega's in binnen- en buitenland, als leerlingen, als vrienden allen.

Lieven Ferdinand de Beaufort werd geboren de 23 e Máart i879 te Leusden, als zoon van den staatsman en historicus Mr. W. H. DE Beaufort. Reeds vroeg trok hem de natuur, die hem door zijn opgroeien op het buiten „Den Treek” bij Amersfoort zo nabij was. Na de H.B.S. te Amersfoort en het z.g. Staatsexamen in 1899 volgde de studie aan de Universiteit te Amsterdam, waar Max Weber en Sluiter de dierkunde, Hugo de Vries en VerschafFELT de plantkunde doceerden en waar de andere jubilaris, die met dit feestnummer gehuldigd wordt, met de Bussy, Weevers, Versluys, Cramer, vaN Kampen, Docters van Leeuwen en Johanna Westerdijk tot zijn studiegenoten behoorde. Reeds dadelijk viel hij op en zo was het, dat hij uitgekozen wend om na zijn candidaatsexamen in 1902, als zoöloog deel te nemen aan de re Nederlandse Nieuw-Guinea-Expeditie onder leiding van Prof. Dr. A. Wichmann. Rijk waren de ervaringen en avonturen in het toen nog zo goed als onbekende gebied, waar een beschieting der reizigers met pijlen door de wilde Papoea's tot de spannendste momenten behoorde. Rijk ook waren de meegebrachte collecties, wier bewerking gepubliceerd werd in het nieuwe tijdschrift „Nova Guinea” en waarvan de verzamelaar zelf de vogels bewerkte in het $5 \mathrm{e}$ deel.

Naar vogels is altijd zijn hart uitgegaan en over vogels waren dan ook zijn eerste publicaties, maar als enthousiast leerling en medewerker van Prof. WebER waren het weldra ook de vissen, die zijn blijvende belangstelling verwierven.

$\mathrm{Na}$ zijn terugkeer uit Nieuw-Guinea werd hij onmiddellijk assistent met de titel van conservator bij Prof. Weber aan het Zoölogisch Museum te Amsterdam. Hier was het ook, dat hij zijn poefschrift bewerkte „De Zwemblaas der Malacopterygii", waarop hij de 9e Juli 1908 promoveerde. In I907 was hij gehuwd met Cathérina Joséphina Boissevain, met wie hij na zijn promotie wederom naar Oostelijk Oost-Indië reisde: Waigeu en Ceram waren het doel van deze verzameltocht, die van I909 tot I9lo duurde en waarvan de resultaten door hem gepubliceerd werden in deel 19 van de „Bijdragen tot de Dier- 
kunde". De vriendschappelijke samenwerking met Prof. Weber leidde er toe, dat de jonge onderzoeker zich met zijn vrouw in Eerbeek vestigde, waar Prof. WEBER op het Huis te Eerbeek zijn particulier laboratorium had en zijn grote ichthyologische bibliotheek, zodat de beide ge.eerden zich daar ongestoord konden wijden aan de voorbereidingen tot het grote werk, dat hun naam over de gehele wereld als leidende ichthyologen zou vestigen. In I9I I verscheen het eerste deel van „The Fishes of the Indo-Australian Archipelago”, in welk werk op systematische wijze in de achtereenvolgende delen de verschillende in OostIndië voorkomende vissenfamilies werden beschreven. Zeven delen was het ,hem vergund met zijn vereerde leermeester samen te publiceren. In latere jaren zette hij, tussen zijn drukke professorale en administratieve werkzaamheden door, de publicatie alleen met onverflauwde ijver voort. Moge, is de wens van alle geinteresseerden, het hem gegeven zijn in de rust van het emeritaat dit belangrijke werk tot een goed einde te brengen.

Ondertussen werden, dikwijls in samenverking met Prof. Weber, tussen de genoemde arbeid door, verschillende publicaties door hem uitgegeven, als resultaat van de bewarking der verzamelingen, die voor de studie der Indische vissen door anderen gemaakt waren.

Ook vogels en zoogdieren op die reizen verzameld werden door hem bewerkt. Voorts werd hem verzocht mede te werken aan de bekende Encyclopaedie van Nederlandsch-Indië.

In 1918 verhuisde het gez.n de Beaufort naar „Den Treek” te Leusden en in 1922 naar „De Hooge Kleij” aldaar. Onverflauwd echter ging de samenwerking tussen den honorair-conservator van het Zoölogisch Museum en zijn hoogleraar voort.

Toen in 1919 een Staatscommissie voor de Visscherij-Inspectie werd ingesteld, was het Dr. DE BEAUfort, wien verzocht werd als secretaris op te treden. De hierdoor geschapen gelegenheid tot practische toepassing van zijn ichthyologische kennis stelde hem in staat te tonen geenszins een kamergeleende te zijn en bezorgde hem in 1922 de benoeming tot Ridder in de Orde van OranjeNassau. Vanzelfsprekend werd hij daarna lid van het College voor de Visscherijen.

Toen in 1922 Prof. Weber aftrad, was Dr. De Beaufort de aangewezen man om hem op te volgen in de leiding van het Zoölogisch Museum. Helaas trof hem, juist vóór hij deze betrekking zou aanvaarden, de zware slag, dat zijn echtgenote, die al die jaren zijn metgezel en hulp bij het werk was geweest, overleed. Met grote ijver echter wijdde hij zich aan zijn nieuwe werk. In 1929 volgde zijn benoeming tot hoogleraar in de Zoögeographie en ook in dit jaar mocht hij zijn tweede echtgenote, Johanna van RaAmsdonk, naar „de Hooge Kleij" voeren, het zo prachtig op de Amersfoortse Berg gelegen huis, met het wijde uitzicht over de Gelderse Vallei, milieu dat hem, den natuurvriend, dagelijks weer verzoende met de lange reis van Amersfoort naar Amsterdam en terug. 
Reeds spoedig kon een begin gemaakt worden met de modernisering van het Museum, een surrogaat voor de plannen tot een nieuw gebouw, die door de eerste wereldoorlog geen voortgang hadden gevonden. Met energie wijdde hij zich aan de taak de tentoonstelling voor het publiek met de hem aangeboren smaak in te richten, want behalve man van wetenschap is onze jubilaris een verdienstelijk tekenaar en schilder, een kant van zijn veelzijdige persoonlijkheid, die, evenals zijn liefde yoor de muziek, slechts aan weinigen bekend is. Met voortvarendheid hielp hij het plan uitvoeren van den preparateur van „Artis", den heer SteEnhuizen, om in de oude collegezaal een duin-diorama in te richten, het bekende Heimans-Diorama, dat met medewerking van de Heimans-Stichting tot stand kwam, en ook hier profiteerde het Museum weer van zijn goede kijk.

Zorgvuldig werden de uitgebreide en belangrijke wetenschappelijke collecties gecatalogiseerd en in de nieuwe bergruimten ondergebracht.

De entomologische afdeling van het museum kreeg met een eigen conservator onderdak in het oude houten gebouw op de Plantage Muidergracht, vroeger als noodgebouw daar neergezet voor het Zoölogisch Laboratorium. Later, met het steeds zich uitbreiden der collecties, werd de entomologische afdeling tijdelijk ondergebracht in het Koloniaal Instituut en, toen men daar zelf meer ruimte nodig had, in een leegstaande Gemeenteschool op de Zeeburgerdijk.

De zorg voor de bestaande collecties, de uitrusting van reizigers met verzamelmateriaal, het uitzoeken en onder de specialisten verdelen van het aldus verworven nieuwe materiaal, de administratie van een museum, dat, begonnen met een staf van 3 man, groeide tot een van 30 man personeel, nam weliswaar veel tijd in beslag, maar onverminderd ging de publicatie van zijn wetenschappelijke onderzoekingen voort. In het begin was er nog altijd de zo zeer beminde samenwerking met Prof. Weber, die periodiek uit Eerbeek overikwam voor enkele dagen, om het gezamenlijke werk te bespreken en die dan aan de koffietafel in "Artis" zijn oudere en jongere leerlingen om zich heen verzamelde.

Op verzoek van de Vereniging tot Behoud van Natuurmonumenten in Nederland nam Prof. DE BEAUfort de leiding op zich tot een eerste inventarisatie van de fauna van het Naardermeer (Jaarboek der Vereen. 1923-'28).

De Maatschappij tot Bevordering van het Natuurkundig Onderzoek in de Nederlandsche Koloniën legde beslag op zijn ervaring als reiziger en zijn kennis van de desiderata. De Nederlandse Ornithologische Vereniging, die hij eerst jaren lang als secretaris diende, benoemde hem in 1924 tot haar voorzitter, een functie, die hij tot nu toe met enthousiasme vervulde. Als zodanig schreef hij ook vele biographieën van Nederlandse ornithologen. De Vereniging drukte haar dankbaarheid uit door hem op een ter zijner ere uitgeschreven feestvergadering op 5 Maart 1.1. tot erelid te benoemen.

Weldra koos ook het Aardrijkskundig Genootschap hem in zijn bestuur en ook daar waren het weer zijn rustige en altijd opgewekte tact en zijn kennis, die hem in later jaren tot de aangewezen voorzitter makten. Zo koos ook de 
Vereniging Museumdag hem tot bestuurslid, werd hij aangezocht zitting te nemen in het bestuur van het Zoölogisch Insulinde-Fonds en aangewezen om mede leiding te geven aan de Organisatie Toegepast Natuurwetenschappelijk Onderzoek. Ook werd hij lid van de Commissie van Advies voor de Afdeling Tropische Producten der Koninklijke Vereniging Indisch Instituut en voorzitter van de Commissie ter Bestudering van Middelen tot Bestrijding van de Rupsenplaag in Amsterdam.

In 1929 bezocht hij als regeringsgedelegeerde het Pacific Science Congress op Java en van December 1937 tot Januari 1938 maakte hij op uitnodiging een reis naar Brits-Indië tot bijwoning van het Indian Science Congress. Men wilde n.l. uiting geven aan de waardering voor zijn werk over de vissen van de Indische Oceaan. Daarom ook ontving hij in 1946 de Golden Joy Gobind Law Memorial Medal for Asiatic Researches in Zoology.van de Royal Asiatic Society of Bengal. Ook door andere instellingen werd van waardering blijk gegeven: zo benoemde hem de Hollandsche Maatschappij der Wetenschappen tot lid, werd hij, nadat hij het 7e Internationale Ornithologen Congres in $193^{\circ}$ te Amsterdam met groot succes als Secretaris had georganiseerd, benoemd tot Ehrenmitglied des Bundes der Ungarischen Ornithologen, zowel als der Ornithologische Gesellschaft in Bayern. In datzelfde jaar benoemde hem de Koninklijke Natuurkundige Vereniging in Nederlandsch-Indië tot corresponderend lid, in 1938 de Zoological Society te Londen. Ook werd hij 1938 Honorary Silver Jubilee Member of the Indian Science Congress Association en in 1946 Honorary Foreign Member of the American Society of Ichthyologists and Herpetologists, terwijl hij in 1948 tot Honorair medewerker van 's Lands Plantentuin te Buitenzorg werd aangezocht en tot Buitenlands Lid der Koninklijke Vlaamse Academie van Wetenschappen, Letteren en Schone Kunsten van België werd benoemd.

Wekelijks gaf hij aan de studenten zijn colleges over de zoögeographie, de syslematiek der vogels of der vissen en voor de studenten ook organiseerde hij buitenlandse excursies naar het vogeltrekstation te Rossitten op de Kurische Nehrung en naar het Belgische Hydrobiologische Station te Buzenol, waar ook weer zijn vermogen ongemerkt te organiseren en een prettige sfeer te verwekken deze reizen tot de aangenaamste herinneringen voor de deelnemers maakten. Later werd hij ook belast met de colleges over der Pharmaceutische Zoölogie en nam hij in de Verenigde Faculteiten van Wis- en Natuurkunde en Letteren en Wijsbegeerte deel aan de opleiding der geografen.

Wie zijn „Zoögeographie van den Indischen Archipel” (1926, Volksuniversiteitsbibliotheek) en zijn „Zoögeographie" (1943, no. I5 in Noorduijn's Wetenschappelijke Reeks) kent, begrijpt, dat zijn heldere en overzichtelijke colleges door de studenten gewaardeerd werden; ook vonden zij in hem een redelijk en humaan examinator. In het Leerboek der Bijzondere Dierkunde, onder redactie van J. E. .W. Ihle en H. F. Nierstrasz, bewerkte hij de Vissen en de Zoogdieren. 
Na de dood van Prof. Weber rustte op hem ook de verdere uitgave van de Monographieën der Siboga-Expeditie. Maar naast dit alles vond hij tijd om voort te werken aan de Indische vissen, daarnaast voortdurend zijn wetenschappelijke onderzoekingen publicerende over zoogdieren, vogels, vissen, zowel fossiele als recente, en over allerlei zoögeographische problemen.

Zijn nuchtere aard behoedde hem er voor eenzijdige hypotheses aan te han-

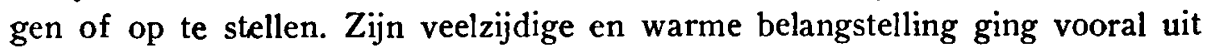
naar het levende dier. Daarom ook kon hij geen dor systematicus zijn. Het Museum was hem slechts archief en illustratie van de levende natuur. Deze zelf had zijn hart in al haar rijkdom en veelzijdigheid, en wie met hem mocht rondwandelen op excursie of in de omgeving van zijn huis, kon zijn liefde voor het dier en zijn scherp waarnemingsvermogen bewonderen.

$\mathrm{Had}$ hij als jong onderzoeker reeds deelgenomen aan het Onderzoek der Zuiderzee, toen besloten werd de verandering van de Fauna te bestuderen, die zou optreden als een gevolg van de drooglegging, was hij het weer, die een werkzaam aandeel in de organisatie en uitvoering van dit onderzoek had. Ook thans telt de Zuiderzeeraad hem onder zijn leden.

Talrijk zijn de reizigers, die zich tot hem wendden voor de organisatie van hun wetenschappelijke reizen; als resultaat hiervan verrijkten de Karakorum Expeditie, de reizen van Prof. Kleiweg de ZwaAn naar Oost-Indië, die van VAN DER Horst en van WagenaAR Hummelinck naar West-Indië en vele andere de collecties van het Museum.

Met hoeveel optimisme en vindingrijkheid de Directeur zich ook aan de onvoldoende behuizing van het Museum heeft aangepast, toch mag niet worden verheeld, hoezeer het hem heeft teleurgesteld, dat het niel gekomen is tot een groot Zoölogisch Museum, dat de ruimte biedt, die voor wetenschappelijk onderzoek vereist wordt en tevens gelegenheid geeft de resultaten van dit onderzoek in ruime kring te populariseren.

Zijn enthousiaste en altijd weer een goede oplossing vindende belangstel!ing, makkte het tot een nooit verflauwende vreugde onder hem te werken. Voor allen en alles had hij immer tijd en belangstelling, gewichtige spreekuren of moeizaam te benaderen afzondering verfoeide hij. Dank zij hem werd geen man van het personeel gedurende de oorlog weggevoerd.

Wie de aangename geest op het Museum kent, die altijd weer de zoölogen daarheen lokt, wie de goede stemming en de toewijding van al het personeel van hoog tot laag kent, beseft, dat hier een systeem is gevolgd, tot de toepassing waarvan weliswaar slechts een wijs en onzelfzuchtig hart in staat is, maar dat de rijkste vruchten afwerpt. Onzelfzuchtigheid immers is wel een der grootste deugden van den jubilaris, die over eigen moeilijkheden nooit spreekt, al bleven ook deze hem allerminst gespaard. Voor de moeilijkheden van zijn personeel echter stond hij immer open. Ieder is altijd overtuigd, dat er rechtvaardigheid, milde menselijkheid en warme belangstelling heerst, ieder is altijd bereid het zijne te geven aan het Museum, dat zozeer het hart heeft van hem, 
die allen beminnen en vereren. Zo was het hem mogelijk het Museum niet alleen een middelpunt van wetenschap, maar ook van practische en populaire voorlichting te doen zijn. Aan zijn initiatief danken wij de rondleidingen van onderwijzers en scholen. Zijn liefde voor natuur en museum wist hij op de suppoosten over te planten, die zich tot voortreffelijke rondleiders ontwikkelden. Geen wonder, dat ook hij, die zijn steun en medewerking reeds bij zovele tentoonstellingen had gegeven, tot Voorzitter benoemd werd van de Gemeentelijke Heemkennis Commissie. Voor haar organiseerde hij de Walvistentonnstelling en de tentoonstelling over haar werk in de Waag, aan zijn enthousiaste ondersteuning van de plannen is het tot stand komen van haar nieuwe blad „Ons Amsterdam" te danken.

Als lid en daarna als secretaris had hij ook jarenlang een actief deel in de werkzaamheid van het bestuur van het Koninklijk Zoölogisch Genootschap Natura Artis Magistra. Groot zijn de voordelen, verbonden aan het nauwe contact van het Museum met de Diergaarde en met het Zoölogisch Laboratorium, welk contact te Amsterdam ook in letterlijke zin nauw is, in verband met het op één en hetzelfde terrein gehuisvest zijn dezer drie instellingen. Bij een dergelijk nauw contact is voor de instandhouding ener behoorlijke samen-werking enige tact van de zijde van alle drie betrokken instanties een conditio sine qua non. Ook in dit opzicht was onze jubilaris weer bij uitstek geschikt zijn deel bij te dragen tot het handhaven van de juiste toon en van de meest aangename samenwerking.

$\mathrm{Zij}$, die dagelijks met $\mathrm{U}$ omgingen, lief en leed met $\mathrm{U}$ mochten delen, weten wat gij alles voor het Museum gedaan hebt, wat gij, ondanks moeilijke omstandigheden, hebt tot stand gebracht en zijn dankbaar hier te mogen getuigen van het voorrecht, dat zij hadden, te werken onder een man met een groot en nobel hart en met een ruime, alles omvattende belangstelling.

$U w$ vele leerlingen en vrienden hebben gemeend $U$ niet beter te kunnen eren, dan door een bijdrage in deze bundel, die een symbool moge zijn van die wetenschappelijke geest, waarmede gij $U w$ leerlingen wist te inspireren en die $U$ met Uwe vrienden vereent.

H. ENGEL 